\title{
NARRATIVAS: FERRAMENTAS DO CAMPO PATRIMONIAL E POTÊNCIAS DE VIDAS
}

\author{
- RAQUEL ALVARENGA SENA VENERA \\ http://orcid.org/0000-0001-7928-0030 \\ Universidade da Região de Joinville \\ - ROBERTA FERNANDES BURITI \\ https://orcid.org/0000-0001-9150-886X \\ Rede Municipal de Educação de São Francisco do Sul
}

RESUMO O uso das narrativas como ferramentas que funcionam como justificativas técnicas para os registros e/ou tombamentos de bens culturais é evidente nos processos e nos discursos do campo do patrimônio. Este artigo apresenta duas narrativas de vida que circulam fora do campo, mas destacam como no cotidiano da vida elas têm se mostrado potências nas situações de reconfiguração identitária e de força em situações de vulnerabilidade. Essas narrativas foram selecionadas por meio de duas histórias de vida coletadas em pesquisa, por meio da metodologia história oral de vida. Trata-se de dois jovens que vivem suas vidas em condição crônica de doença desde que foram diagnosticados com esclerose múltipla e escolheram sistematizar essas experiências em narrativas e socializá-las em blogs. Essas narrativas não só os uniram como criaram uma comunidade capaz de capilarizar um movimento ativista em rede. Ressaltam, portanto, um valor incontestável para pô-las no centro da discussão sobre as funções sociais dos patrimônios pensados pelas, com e para as pessoas. $O$ artigo é uma defesa de patrimônios pensados levando em conta as riquezas humanas vivas, capazes de produzir identidades e experiências existenciais de escuta e alteridade, além de posicionar-se, elas mesmas, como patrimônios da humanidade.

Palavras-chave: Patrimônio. Narrativas de vida. História oral de vida. Ciberespaço. Esclerose múltipla.

\section{ABSTRACT NARRATIVES: HERITAGE TOOLS AND LIFE POWERS}

The use of narratives as tools that function as technical justifications for the records and or tipping of cultural goods are evident in the processes and discourses of the field of heritage. However, this article presents two narratives of lives circulating outside the field, but 
evidence how in everyday life they have proved to be powers in situations of identity reconfiguration and strength in situations of vulnerability. These narratives were selected from two life stories collected in a research situation through the oral history of life methodology. These are two young people who have lived their lives in chronic disease condition since they were diagnosed with Multiple Sclerosis and chose to systematize these experiences in narratives and socialize them on blogs. These narratives not only brought them together but created a community capable of capillarizing a networked activist movement. They therefore show an undeniable value to put them at the center of the discussion about the social functions of assets thought of by, with and for people. The article is a defense of heritage thought from living human riches, capable of producing existential identities and experiences of listening and otherness, in addition to putting them themselves as Humanity Heritage.

Keywords: Heritage. Narratives of lives. Oral History of life. Cyberspace. Multiple Sclerosis.

\section{NARRATIVAS: HERRAMIENTAS DEL CAMPO PATRIMONIAL Y PODERES DE LA VIDA}

El uso de las narrativas como herramientas que funcionan como justificaciones técnicas para los registros y o la propina de bienes culturales son evidentes en los procesos y discursos del campo del patrimonio. Sin embargo, este artículo presenta dos narrativas de vidas que circulan fuera del campo, pero evidencian cómo en la vida diaria han demostrado potencias en situaciones de reconfiguración de identidad y fuerza en situaciones de vulnerabilidad. Estas narrativas fueron seleccionadas de dos historias de vida, recopiladas en una situación de investigación, a través de la metodología de la historia oral de la vida. Se trata de dos jóvenes que han vivido sus vidas en estado crónico desde que fueron diagnosticados con Esclerosis Múltiple y optaron por sistematizar estas experiencias en narrativas y socializarlas en blogs. Estas narrativas no sólo los unieron, sino que crearon una comunidad capaz de capilarizar un movimiento activista en red. Por lo tanto, muestran un valor innegable para ponerlos en el centro de la discusión sobre las funciones sociales de las patrimonies que piensan, con y para las personas. El artículo es una defensa de los patrimonios pensados a partir de riquezas humanas vivas, capaces de producir identidades existenciales y experiencias de escucha y de otra cosa, además de ponerlas a sí mismas como Patrimonio de la Humanidad.

Palabras clave: Patrimonio. Narrativas de vidas. Historia oral de la vida. Ciberespacio. Esclerosis Múltiple. 


\section{Narrativas e patrimônio cultural}

Sempre haverá alguém querendo confiscar nossa humanidade, [...] mas permaneceremos unidos, em comunidade de compartilhamento para que nossas histórias nos restaurem. Viver em voz alta é expandir a vida de todxs [...] (SILVEIRA, 2019)

Não é mais novidade dizer que as narrativas são centrais no campo do patrimônio cultural. Elas são práticas sociais consideradas como tesouros vivos capazes de trazer significações para a materialidade dos bens patrimoniais. Nos processos de patrimonialização dos bens culturais, os valores que lhes são atribuídos e os critérios adotados para aferi-los levam em conta, por vezes, o valor representativo de uma coletividade, e as análises técnicas do processo incluem a expressão da memória social e histórica do grupo social e suas narrativas de memória, coletadas por meio de métodos científicos, para justificar a patrimonialização do bem e aferir a legitimidade que confere o valor artístico, arquitetônico, histórico e arqueológico. Dizendo de outra forma, as narrativas potencializam o reconhecimento do bem e são tecidas para estabelecer o significado de pertencimento coletivo, seja ele material, seja imaterial. Sendo assim, as narrativas que legitimam um bem como patrimônio são construídas do compartilhamento de experiências representativas de memórias e identidades, e os objetos, espaços, edificações e/ou práticas, saberes ou modos de vida buscam representar origens étnicas, valores sociais, culturais ou religiosos de segmentos sociais. A inter-relação entre as dimensões material e imaterial desses bens é intrínseca e está diretamente ligada às narrativas de memória construídas social e historicamente sobre os bens.

Tampouco é novidade o reconhecimento das narrativas das vidas das pessoas, ou as histórias de vida, no campo do patrimônio cul- tural. Como afirmou Chauí (1989, p. 113-114), o trabalho, a religião, a culinária, o vestuário, o mobiliário, as formas de habitação, os hábitos à mesa, as cerimônias, o modo de relacionarse com os mais velhos e os mais jovens, com os animais e com a terra, os utensílios, as técnicas, as instituições sociais (como família) e políticas (como Estado), os costumes diante da morte, a guerra, as ciências, a filosofia, as artes, os jogos, as festas, os tribunais, as relações amorosas, as diferenças sexuais e étnicas, tudo isso constitui a cultura como invenção da relação com o outro. Ou seja, a riqueza das experiências das pessoas no tempo é expressa nas narrativas que constroem sobre suas vidas. É o que mostra, por exemplo, o trabalho patrimonial do Museu da Pessoa, em São Paulo, instituição que produz, preserva e dissemina as histórias de vida. Szymczak e Venera (2019), no artigo "A ativação valorativa das histórias de vidas no Museu da Pessoa", refletem acerca do reconhecimento das histórias de vida de pessoas ordinárias como um patrimônio comum da humanidade e como se ativam os valores patrimoniais presentes nessas histórias de vida. Entre todos os motivos que nos levam a enxergar o valor social e histórico de uma história de vida, está a necessidade humana de se reconhecer como um ser social de compartilhamento pela linguagem.

Outro exemplo desse reconhecimento é o Programa Tesouros Humanos Vivos, da Organização das Nações Unidas para a Educação, a Ciência e a Cultura (Unesco), influenciado pelas políticas japonesas de patrimônio imaterial. Essa prática patrimonial é focada na valorização das expressões da cultura popular e tradicional, na transmissão de saberes, na busca de salvaguardar as tradições culturais coletivas que estão ameaçadas de desaparecimento ou extinção. Para tanto se faz a pre- 
servação pelo registro de memórias, saberes e práticas de pessoas ou grupos, baseando-se no entendimento de que ambos são patrimônios vivos. Trata-se de uma política que representou uma mudança significativa na perspectiva das ações de salvaguarda dos patrimônios imateriais, principalmente pelo fato de ampliar o objeto de proteção, que deixou de ser focado só nas expressões culturais e passou a ser também voltado para as pessoas ou os grupos de pessoas detentoras de conhecimentos e práticas tradicionais (VALENÇA, 2014, p. 21). 0 título de "patrimônio vivo" é dado a uma pessoa ou um grupo que detém saberes e práticas culturais tradicionais.

Nessa esteira, no estado brasileiro de Pernambuco, a Lei n.o 12.196/2002 institucionalizou o Registro do Patrimônio Vivo, uma ação de apoio direto às condições de vida de pessoas e grupos de pessoas, garantindo por meio de bolsas vitalícias melhores condições para a produção e reprodução de seus saberes e fazeres, além de sua inserção na política pública de cultura.

A Unesco já há algum tempo vem discutindo meios e políticas para proteger o patrimônio cultural imaterial, especialmente depois da Convenção de 1972, quando a proteção do patrimônio natural e cultural do mundo foi assunto de discussões: como expandir a proteção não apenas como patrimônio não material, mas sobretudo um patrimônio vivo? O documento chamado Recomendação para a Salvaguarda da Cultura Tradicional e do Folclore, não obrigatório, foi aprovado posteriormente, em 1989, e nos anos seguintes a Unesco começou a desenvolver uma série de programas, entre eles o Tesouros Humanos Vivos, em 1993; e o Obras -Primas do Patrimônio Oral e Intangivel da Humanidade, em 1997 (TAYLOR, 2011, p. 94).

Além desses reconhecimentos das narrativas de vida no campo do patrimônio, este artigo procura evidenciar situações em que as narrati- vas funcionaram como ferramentas existenciais em condições de vulnerabilidade no cotidiano, no qual a vida se faz. Em tempos de comunicação na rede mundial de computadores, essas narrativas de vida hiperdimensionam-se, podendo ganhar a função social de restaurar dignidades humanas, como anunciado na epígrafe do presente texto. No atual contexto de socialização de narrativas de vida no ciberespaço, procuramos destacar o potencial das narrativas de memória integrado ao movimento da vida e dos seus processos de aprendizagem. Os exemplos trabalhados aqui foram coletados em situações de pesquisa'. Trata-se da experiência virtual nas histórias de vida de dois blogueiros - Bruna e Jota - que sobressaem em comunidades narrativas. São exemplares de grupos/ pessoas que usam o ciberespaço para disseminar seus ativismos em práticas narrativas de vida haja vista sua relação com a vulnerabilidade e uma condição de cronicidade de saúde/ doença. Ambos restauram suas vidas por meio da reorganização de memórias e identidades e, por sua vez, aprendizagens sobre si.

O exercício do artigo é uma aposta ao elogio das narrativas ou histórias de vida no cotidiano e, sobretudo, destaca a potência dessa prática humana como restauradora de vidas e tesouro da humanidade.

1 Trata-se da pesquisa de dissertação intitulada Aprender a viver com a doença: narrativas (auto)biográficas, valores patrimoniais e ciberespaço, que esteve vinculada às pesquisas Memórias Múltiplas e Patrimônio Cultural em Rede: o Desafio (Auto)Biográfico diante da Ameaça da Perda, aprovada pelo Parecer Consubstanciado do Comitê de Ética em Pesquisa (CEP) n.o 993.242, de 27 de março de 2015. A pesquisa criou e alimenta a Coleção Histórias de Vidas com Esclerose Múltipla, do acervo do Museu da Pessoa, São Paulo. Possui financiamento da Fundação de Amparo à Pesquisa do Estado de Santa Catarina (Fapesc) n.o 06/2017 e do Fundo de Apoio à Pesquisa (FAP) da Universidade da Região de Joinville (Univille). Esse corpus empírico está vinculado também à pesquisa (Auto)biografias e subjetividades: o outro de si mesmo na esclerose múltipla, com financiamento do Conselho Nacional de Desenvolvimento Científico e Tecnológico (CNPq)/da Coordenação de Aperfeiçoamento de Pessoal de Nível Superior (Capes), processo n.o 40.7921/2016-8. 


\section{Por que ferramentas?}

Ao refletirmos sobre o caráter memorial e funcional dos acervos de histórias de vida, percebemos que a construção de uma realidade memorial é criada, como afirma Joël Candau (2011), mediante atos declaratórios. Por sua vez, a salvaguarda dessa memória social é entendida como um legado. Esse legado, do qual nos fala Candau (2011), possui relações íntimas entre a memória e o tempo.

As narrativas de memória são sempre coletadas em um tempo presente que convoca lembranças de um passado em função de expectativas de futuro. Nesse processo de constituição de fontes de memória, sabemos que fatores sincrônicos e diacrônicos influenciam diretamente na escolha de memórias que devem ser consideradas e transmitidas. Koselleck (2014) afirma que existe uma ligação entre o tempo da vida e o tempo histórico coletivo. Os horizontes de expectativas estruturam-se entre as temporalidades, nas quais o passado é entendido como o "campo da experiência", o presente consiste no "lugar de gestação do amanhã", e o passado e o futuro são ressignificados pelo presente. Sendo assim, o futuro representa o horizonte de expectativas (KOSELLECK, 2014, p. 305-314). A experiência é o passado atual, aquele ao qual acontecimentos foram incorporados e podem ser lembrados. Na experiência se fundem tanto a elaboração racional quanto as formas inconscientes de comportamento, que não estão mais, ou que não precisam mais estar presentes no conhecimento. Além disso, na experiência de cada um, transmitida por gerações e instituições, sempre está contida e é conservada uma experiência alheia. Nesse sentido, também a história é desde sempre concedida como conhecimento de experiências alheias (KOSELLECK, 2014, p. 309).

Nessa dinâmica da temporalidade estruturada por Koselleck (2014), a reflexão his- toriográfica e filosófica sobre a relação existente entre as temporalidades e as memórias nos dá a noção de como nos relacionamos com o tempo e com a constituição de nossas memórias. E, como a narrativa é um legado de estrutura temporal, ao refletirmos sobre essa dinâmica da temporalidade, verificamos que Koselleck (2014) constrói essa noção de tempo mediante o estudo das narrativas, em que as múltiplas leituras dos fatores sincrônicos e diacrônicos históricos compõem essa consciência social.

Logo, diversos aspectos influenciam na formação e no processo de compreensão da história (a ideologia, a organização política, o gênero, a família, a classe), e esse processo é avaliado na dinâmica da temporalidade histórica (passado, presente e futuro), que é um fator determinante para a compreensão das mudanças ocorridas na concepção de conceitos históricos fundamentais para a estruturação da história. A constituição de memórias pelo processo de patrimonialização apresenta a função social de consciência temporal, entendendo a política de patrimonialização como um meio de socialização de experiências e de combate às injustiças e violências sociais em que "devemos trabalhar de forma que a memória coletiva sirva para a libertação e não para a servidão dos homens" (LE GOFF, 2003, p. 471).

Parte dessa memória social é preservada por intermédio de bens patrimoniais, os quais apresentam valores humanos que são construídos socialmente: a "memória coletiva tira sua força e sua duração por ter como base um conjunto de pessoas, são os indivíduos que se lembram, enquanto integrantes do grupo" (HALBWACHS, 2006, p. 69). Entende-se, portanto, que a memória social é um sistema vivo e regulador, já que a memória social sofre constantes reconstituições a cada momento em que o acontecimento é rememorado. 
Esse é o processo da constituição da história de vida de um indivíduo, a qual se torna mais evidente diante de situações de trauma e vulnerabilidade, pois, diante da ameaça da perda, o indivíduo evoca suas lembranças sociais para afirmar sua memória e, por sua vez, sua identidade. Segundo Halbwachs (2006), para que a nossa memória se aproveite da memória dos outros, não basta que estes nos apresentem seus testemunhos. Também é preciso que ela não tenha deixado de concordar com as memórias deles e que existam muitos pontos de contato entre ambas. Ou seja, as lembranças em comum devem ser constituídas sobre uma base comum (HALBWACHS, 2006, p. 39). Dizendo de outra forma, as narrativas de memória que atravessam os patrimônios culturais respondem aos horizontes de expectativas pensadas para outras gerações. Nesse entendimento, reconhecemos histórias de vida como patrimônio da humanidade, como fontes de saber.

De acordo com Thompson (2006), a história de vida pode ser entendida como patrimônio da humanidade, pois é considerada atualmente parte essencial de nosso patrimônio cultural. Essa é "uma situação muito nova e, olhando para o futuro, acho que há possibilidades imensas, por exemplo, para criar novas conexões entre as pessoas em mundos sociais e geográficos diferentes; através do oral, criando novas solidariedades e novos entendimentos" (THOMPSON, 2006, p. 19). O imbricamento dos meios de comunicação tem se tornado cada vez mais comum, potencializa mudanças significativas na forma como processamos as informações disponíveis e conecta pessoas pela rede haja vista seus centros de interesse. A integração dos elementos comunicacionais em ambientes virtuais traz para o panorama histórico, político e social novas configurações que são pautadas em uma cultura tecnológica.
Levando em conta todos esses pressupostos, a palavra ferramenta parece vir dessa cultura em que tudo que se faz está mediado ou é a própria tecnologia. Nesses espaços virtuais, nos quais se configuram as comunidades de compartilhamento ou comunidades narrativas, as narrativas funcionam como ferramentas dessa tecnologia a serviço da memória e das identidades dos sujeitos. Algo que se mobiliza para fazer funcionar as ações planejadas. Sem perder de vista as reflexões de Koselleck (2014) quando apresenta as narrativas como "lugar de gestação do amanhã", é importante dizer que elas funcionam, nos exemplos apresentados neste artigo, como apostas de um novo pacto civilizatório para horizontes de expectativas de outro mundo possivel, onde as vulnerabilidades humanas não funcionam como gatilhos de inferioridade nos arranjos das identidades, mas, antes, como condição da vida de todos.

\section{Compartilhamento restaurador ou viver em voz alta}

Bruna e Jota são dois jovens que, após serem diagnosticados com esclerose múltipla, decidiram compartilhar suas histórias de vida em blogs. Para Bruna, a ideia de compartilhar suas experiências, suas dores e como vem aprendendo a viver com a doença surgiu após a sugestão de amigos que ouviram seus testemunhos de vida e tiveram uma perspectiva diferente de como conviver com a doença. Esses amigos, colegas da pós-graduação à época, incentivaram-na a compartilhar suas histórias de vida, pois, assim como ela, existem também outros jovens que, ao receberam o diagnóstico de esclerose múltipla, estavam no auge de suas expectativas sobre o futuro da vida e carreiras. Esse fato é característico da doença, como apontado em Atlas da Esclerose Múltipla, organizado pela Multiple Sclerosis International Federation (2013, p. 10). Na maioria das 
vezes, a esclerose múltipla atinge pessoas no momento em que elas estão estruturando sua carreira, encontrando um parceiro permanente ou tendo filhos. A doença pode, portanto, gerar impacto sobre o bem-estar econômico e social das pessoas, bem como sobre seus familiares e parceiros.

Assim, incentivada por amigos e familiares, aos 22 anos de idade, entendendo o ciberespaço como um potente espaço narrativo, Bruna criou o primeiro blog do Brasil que fala sobre esclerose múltipla, sob o nome Esclerose Múltipla e Eu. Nesse espaço ela revela questões que fazem parte do viver com uma doença crônica, as causas, os sinais e sintomas da doença, os fatores de risco e fala também sobre o processo de conviver com as restrições e limitações advindas da doença e como gerenciá-las de maneira a obter melhor qualidade de vida. Ou seja, compartilha relatos de sua vida, seus aprendizados, seus desafios emocionais e sociais, cada conquista pessoal, notícias médicas que impactam a vida das pessoas doentes, entre outras questões cotidianas.

Depois de muito pensar, resolvi montar esse blog contando histórias do meu dia a dia, minhas frustrações e felicidades como portadora de Esclerose Múltipla [EM]. Penso em assim ajudar todas as pessoas que têm essa doença e que muitas vezes sentem-se perdidos. Acho que hoje já estou preparada para falar da minha doença, minhas dores, minhas dificuldades com maturidade, aceitando o meu "destino". [...] Gostaria muito da contribuição de vocês portadores de EM ou não, para que esse blog seja rico em informações úteis para o nosso cotidiano. Além da minha vida, quero dividir com vocês as pesquisas feitas no mundo todo sobre EM, nossos direitos, tratamentos, terapias alternativas, etc. (SILVEIRA, 2009).

Bruna revela no blog a sua trajetória de vida, os alicerces de sua identidade, mobilizando saberes, em constante estado de agenciamento, como um processo de partilha sen- sivel de experiências e saberes com as suas diferenças. À sua tese de doutorado, ela atribuiu o seguinte título: Dor compartilhada é dor diminuída, afirmando que "é necessário que consigamos contar nossas histórias porque é nelas que está o alicerce de nossas identidades" (SILVEIRA, 2016, p. 50). Segundo seu argumento, esse é o potencial das narrativas (auto) biográficas.

Ao dividir com o outro suas dores, conquistas, desafios, aprendizagens com a doença e a sua condição humana na rede, Bruna percebeu que a potência desse partilhar está na estruturação de uma rede de apoio para ela e para os que leem suas narrativas. Em seu post "Porquê escrevo", a jovem explicou os motivos que a levaram a escrever: "É por isso também que eu escrevo. Porque algumas coisas me devoram permanentemente, e a minha forma de lidar com isso é colocando pra fora, é compartilhando com vocês. E agradeço, imensamente, por não me deixarem sozinha" (SILVEIRA, 2014b). Bruna reconhece que ao compartilhar suas narrativas cria uma forma de lidar com seus sentimentos e de se conhecer. Um pouco da afirmação de Foucault (2010, p. 6) quando diz: “É preciso que te ocupes contigo mesmo, que não te esqueças de ti mesmo, que tenhas cuidado contigo mesmo". Muchail (2011) também reflete sobre esse cuidado de si: cuidar-se não é um privilégio, nem dever de alguns para o governo de outros; é imperativo para todos.

Cuidar-se não se endereça a uma fase específica da vida, é tarefa para todo o tempo, e se há alguma etapa que melhor se destina é a maturidade, principalmente a velhice [...]. Cuidar-se não se circunscreve ao vínculo dual e amoroso entre mestre e discípulo, expande-se aos círculos de amizades [...], de parentesco, de profissão, quer em forma individualizada (cartas, aconselhamentos, confidências), quer institucionalizadas e coletivas (escolas, comunidades, etc.). (MUCHAIL, 2011, p. 76) 
Outro blogueiro nessas condições é Jaime, conhecido nas redes sociais como Jota, também diagnosticado com esclerose múltipla e que conheceu Bruna por meio do seu blog. Após ter recebido o diagnóstico, em 2012, decidiu pesquisar na internet sobre a doença. Nessa busca encontrou o blog de Bruna, uma jovem estudante ativa social e profissionalmente, desfrutando experiências que, no seu entendimento, não seria mais possivel, como viajar, estudar e manter uma vida acadêmica ativa. Movido por sua curiosidade, passou a manter contato com ela e, dessa relação, surgiu uma grande amizade, que posteriormente veio a se transformar em um casamento. Hoje, Jota é casado com Bruna e tem um blog na plataforma da associação Amigos Múltiplos pela Esclerose (AME).

Vale explicar que a esclerose múltipla é uma doença do sistema nervoso central classificada em níveis, conforme o grau de comprometimento das inflamações cerebrais e de suas consequências, em forma de sequelas físicas. Jota foi diagnosticado com esclerose múltipla do tipo primária progressiva, que é quando as inflamações e sequelas deixadas pela doença avançam progressivamente sem remissão. Esse tipo de esclerose atinge apenas $10 \%$ dos pacientes. Hoje em dia, ele é cadeirante, lutou judicialmente para o acesso ao único e recente medicamento que the traria melhor qualidade de vida e, no momento da pesquisa, vivia uma frustração, pelo fato de a medicação não ter ainda promovido a remissão esperada. Em seu post "Começando a blogar na AME", Jota relata sobre o que o levou a escrever:

Tive o diagnóstico em 2012 e desde então senti conjuntamente à fadiga uma ebulição para escrever. Foi numa tarde de domingo, em um passeio no Ibirapuera em que a Bruna e o Gustavo me convidaram para fazer parte do grupo de blogueiros da AME. [...] Várias vezes, me via pensando um "preciso escrever sobre isso", ao enfrentar as dificuldades enfrentadas diaria- mente devido a EM. [...] Minhas ideias, elas já borbulhavam invisiveis como ondas de rádio. A AME sintonizou essas ideias e abriu os microfones para esse blogueiro novo no ato de falar da esclerose e sobre a esclerose, mas não inexperiente nos (des)caminhos com a doença. (SANTOS JUNIOR, 2015)

Com o suporte da AME, Jota viu a oportunidade de compartilhar seus medos, anseios, frustrações e questões existenciais, em ebulição na sua mente. No blog, o jovem escreve sobre o que significa viver com uma doença crônica, aponta os seus desafios de conviver com as limitações de uma deficiência e as adaptações que precisa fazer em seu cotidiano para melhorar a sua qualidade de vida e a de sua família. Também demonstra sua gratidão pela rede de apoio que tem disponivel, pois sem ela não teria a qualidade de vida que tem hoje, como podemos perceber em seu post "EM e Família (Parte IV) - Obrigado!":

Devo agradecer aos familiares e amigos que desde o diagnóstico me auxiliaram com caronas, acompanhamentos, apoios, resolução de problemas etc. E, acima de tudo, por me olharem como igual, verem uma pessoa e não uma cadeira de rodas ou uma doença. Por não me fazerem sentir mal por precisar de ajuda. (SANTOS JUNIOR, 2018)

Jota reconhece que essa rede de apoio é culminante para a qualidade de vida da pessoa doente. Ele afirma que, quando se tem uma rede de apoio comprometida, que acompanha os processos dessa adaptação, a rotina diária se torna mais fácil. Entendendo a importância do papel dos cuidadores no seu cotidiano, Jota agradece a todos que dão suporte à sua rotina.

Ele também escreve sobre os seus conflitos existenciais - medos, anseios, sonhos e desejos -, fazendo uma analogia entre a história e suas experiências de vida, por ser o seu campo de interesse acadêmico e pessoal, como podemos observar em seu post "EM e Eu (Parte III) Tempo e privilégio ou o que eu desejo perder": 
$\mathrm{Na}$ literatura, às vezes, a nudez significa uma espécie de rito de passagem. Um momento em que o personagem rasga suas roupas e passa a encarar a realidade de maneira mais sóbria, desvencilhando-se de todas as ilusões. [...] Deixando pra trás todas as vaidades e aparências humanas, sentindo-se seguro em seguir sua própria consciência. Não tenho muito a dar, mas estou nu. Desde 2015, quando comecei a escrever na AME, iniciei um contínuo processo de entendimento, que resultou em uma profunda reinterpretação do que eu era e acreditava ser. Assim, descobri um novo eu, que passou obrigatoriamente por refletir, dar sentido e escrever a experiência com a doença. A exposição pública dos meus temores mais privados foi um tipo de libertação. (SANTOS JUNIOR, 2019)

Jota expressa em seu blog que, apesar dos seus temores com a exposição pública, o fator libertador que a escrita de si trouxe tornou esses temores infimos diante do resultado terapêutico e (auto)formativo. Como casal, Bruna e Jota passaram a escrever sobre questões familiares com esclerose múltipla, suas inseguranças com a maternidade/paternidade e, assim, tornaram-se conhecidos nas redes sociais como o primeiro casal formado por pessoas diagnosticadas com esclerose múltipla de que temos notícia. São pais de Francisco, a primeira criança de pais com esclerose múltipla de que se tem registro. Esse fato faz deles, ao mesmo tempo, únicos e vetores de grande parte das questões e dúvidas cotidianas das pessoas diagnosticadas com a doença. Eles escrevem em seus blogs, mas também gravam vídeos que são postados no YouTube, em que exploram temas banais da vida em mídias convergentes. Os assuntos do dia a dia são sobre pessoas com esclerose múltipla, as adaptações possiveis no caso de sequelas e as relações afetivas com familiares não doentes: namoro, sexo, baladas, gravidez, inseguranças.

No post "Carta ao marido da jovem grávida", Jota escreveu para os papais grávidos e Bruna publicou em seu blog: “E essa é a primeira su- gestão que dou aos maridos: esqueça do futuro, dos medos, dos objetivos. Sua vida é outra agora, tenha medo, mas vá com medo mesmo" (SILVEIRA, 2016a). Bruna e Jota revelam durante suas entrevistas e em seus posts que escrevem suas narrativas (auto)biográficas com a intenção de reelaborarem suas subjetividades e de compartilharem suas dores, como um ato terapêutico, na busca da constituição de si. $\mathrm{O}$ alcance de suas narrativas, porém, ganhou proporções sociais que nenhum dos dois tinha previsto.

Candau (2011, p. 23) destaca que as narrativas identitárias são marcadas de "metamemórias", ou seja, "da representação que cada indivíduo faz de sua própria memória" e da perspectiva ou consciência que se tem de determinado fato. Isso está intrinsecamente relacionado a fatores sociais e culturais presentes antes do fato e que influem na formação da consciência do fato, o que é reconhecido por Candau (2011) como "uma memória reivindicada", capaz de conectar vidas que se identificam, despertar empatia, construir identidades e mobilizar grupos, mesmo que a estratégia da narrativa seja inconsciente. Isso é evidente na experiência de narrativa de Bruna:

Uma vez eu marquei assim no... De brincadeira no blog assim, sabe, tipo: Vamos se encontrar na Redenção? - que é o parque aqui perto de casa - tomar um chimarrão pelo dia mundial da esclerose? Tinha mais de cinquenta pessoas, assim. E eu, tipo, marquei três dias antes, então aquilo me assustou um pouco, sabe. $E$ as pessoas: Ah, Bruna e tal. E eu [inaudivel]. E aí, as pessoas contavam coisas da minha vida para mim. E aí eu: Ah! Meu Deus, verdade, eu escrevi isso. [Inaudivel] Daí vai caindo uma ficha assim... Você... A minha vida... É pública, não é? Minha vida é pública. E aí eu saí no jornal, no jornal... No maior jornal aqui do estado, que é o Zero Hora. Então eu comecei a... Meio que ser uma referência de esclerose múltipla assim e eu achei isso muito bizarro, assim no início. Por que a gente tem a ideia de que a referência de 
doença é o médico, não é? E a gente tem visto isso mudar um pouco nos últimos anos [...] (SILVEIRA; BURITI; VENERA, 2018)

Apreendendo o potencial dessas narrativas identitárias de mobilizar indivíduos e grupos, mesmo que Bruna e Jota não tivessem a intenção de se tornar referenciais, suas narrativas ganharam espaço, voz e visibilidade no meio dos pacientes. Assim, narram suas histórias de vida em busca da compreensão de si, por meio de um falar de si hermenêutico, entendendo a hermenêutica como a forma de o indivíduo refletir sobre a historicidade interna da sua experiência. Na relação com o outro, esse movimento de compreensão é permeado por descobertas, dilemas, confissões, desafios, valores, crenças, peculiaridades, relações e ações para entender que esse processo de autorreflexão faz parte do processo (auto)formativo.

Bruna e Jota veem em suas práticas narrativas um caminho para viver com a doença, reconstruir suas identidades e organizar suas memórias, que estão em constante diálogo com o passado. Como observa Gadamer (1997, p. 416), “a autorreflexão do indivíduo não é mais que uma centelha na corrente cerrada da vida histórica". No caso do casal Bruna e Jota, as suas práticas narrativas, suas reconstruções identitárias e suas reflexões sobre a vida conectam-se e são também de igual importância para os outros, reverberando em comunidades narrativas. Essas narrativas sobre si revelam valores patrimoniais por apresentarem uma função social entre a comunidade de doentes e familiares, assim como no movimento de políticas de inclusão. Eles apresentam para o paciente crônico um caminho para aprender a viver com a doença e a se refazerem (identidade) pelas práticas narrativas (memórias), de acordo com as suas capacidades e limitações.

No post "Classificados esclerosados", Bruna relata a questão do trabalho e a esclerose múltipla, ou seja, um local onde a identidade de pessoa vulnerável acentua sua condição:

Algumas pessoas com [esclerose múltipla] EM conseguem continuar nas suas funções. Outras tem suas funções readaptadas no mesmo local de trabalho. Outras inventam novos trabalhos, porque, infelizmente, vivemos numa sociedade pautada no "normal", em que todos devem seguir um padrão, e, quem não seguir, está fora. Eu tenho certeza que, quando eu estou bem, produzo muito mais e melhor em três turnos por semana que a grande maioria dos "normal", que batem ponto $8 \mathrm{~h}$ por dia. Mas aí, pra convencer um empregador disso [...] difícil! (SILVEIRA, 2015a)

Hoje, Bruna e Jota escrevem sobre como é conviver diariamente com uma doença crônica, sem acessibilidade, em uma sociedade que está aprendendo a lidar com as diferenças e que ainda entende a inclusão apenas sobre o ponto de vista físico, estrutural ou arquitetônico, pois não está habituada a enxergar a inclusão como uma questão social. O movimento que Bruna e Jota promovem, juntamente com a AME, é fazer com que a voz dos pacientes seja levada em consideração no estabelecimento de políticas públicas de inclusão, além de facilitar o acesso à medicação de alto custo e colocar em evidência nas redes sociais a necessidade da inserção de protocolos de atendimento, entre outros fatores.

Com o decorrer dos anos, suas postagens passaram a ser visualizadas por um número cada vez maior de jovens diagnosticados com esclerose múltipla, assim como por familiares e amigos. Hoje o blog de Bruna tem 784 seguidores, com mais de 500 visualizações diárias, e responde diariamente a mais de dez e-mails de novos jovens diagnosticados com a doença. Esse número é expressivo, considerando que a esclerose múltipla está em um universo de pessoas diagnosticadas com doenças raras. Diante de tamanha repercussão, Bruna e Jota passam a ser reconhecidos como influenciadores digitais, ou seja, líderes de opinião. Segundo Morgado 
(2005, p. 120), "a emergência da figura do líder de opinião foi entendida no séc. XVIII como a de um indivíduo que consubstancia numa só pessoa o poder da palavra de muitos. Ele exerce o poder de falar em nome dos pares ou explica a sua visão do que está a acontecer".

Os seus leitores, ao lerem suas narrativas de experiências de vida com uma doença crônica e ao refletirem sobre elas, passam a perceber o processo de adoecimento, bem como suas aprendizagens pessoais e profissionais, e encontram nessas narrativas de experiência um meio terapêutico de enfrentamento das adversidades e de resistência da doença. Os conceitos médicos são colocados em discussão, tratamentos são reavaliados, preconceitos são revistos, medos são superados, e assim novos sentidos da doença e representações sociais podem ser reelaborados. 0 reconhecimento e a valorização dessa troca de saberes por esse público demonstram também a função social que essas narrativas apresentam e possibilitam a visualização de diferentes perspectivas sobre as políticas de inclusão.

No site da AME, Bruna convida-nos a refletir em seu post "Incluir é pra quem?" sobre a sua visão de incluir:

A Inclusão, ou seja, a possibilidade de todos se desenvolverem de forma plena no ambiente familiar, social, escolar ou de trabalho, só é possivel a partir da acessibilidade. [...] É ter uma comunicação acessivel a todos, sejam eles ouvintes ou surdos, cegos ou videntes, com capacidade cognitiva "normal" ou não. É ter uma educação acessivel a todos, com formas de ensino, aprendizagem e avaliação coerentes com cada indivíduo. É ter arquitetura acessivel a todos, para que todos possam circular por onde quiserem. É ter um mercado de trabalho que permita que todos possam exercer as profissões que escolheram, adaptando e adequando espaços, horários e prazos à necessidade de cada um. É ter acessibilidade atitudinal, porque não adianta só colocar rampa nos prédios. (SILVEIRA, 2015b)
Nesse post, Bruna propõe-nos a entender a inclusão além da acessibilidade arquitetônica, mas sim como uma questão social e cultural que envolve valores éticos e morais. Essa concepção de inclusão reivindica que, independentemente das diferenças, físicas, mentais, sociais, étnicas ou econômicas, todos merecem ser respeitados, acolhidos e assistidos socialmente, sem descaso ou segregação, e que a sociedade deve oferecer suportes sociais, físicos, econômicos e instrumentais, para que esse público possa ter acesso a oportunidades que proporcionem condições de participação social com igualdade, entendendo a questão da deficiência não apenas como uma questão biológica, mas principalmente social.

Nesse sentido, suas práticas narrativas passam a fazer parte de um movimento em rede que propõe mudanças nas políticas públicas de inclusão, levando seus leitores a direcionar um novo olhar para a perspectiva que o paciente tem do processo de adoecimento, seus medos e anseios. Ainda, leva-nos a refletir sobre as políticas públicas que foram criadas sem levar em consideração o olhar do paciente, o colocar-se no lugar do outro, ocasionando incompreensões que poderiam ser evitadas, conforme podemos observar no post "Nada sobre nós sem nós", escrito pela Bruna em seu blog:

Vai fazer uma rampa pra cadeirante? Chama um cadeirante pra avaliar onde fica e como fica melhor. Vai escrever um cardápio em braile? Chama alguém com deficiência visual, usuária de braile, pra saber como fica melhor. [...] Médicos sabem muito sobre doenças, [...] mas, eles não sabem o que é viver a doença socialmente. [...] Inclusão é colocar quem vive a diferença no centro das discussões não como objeto, mas como sujeito. (SILVEIRA, 2016b)

Na perspectiva de que é o paciente que vive com a doença no âmbito social, é ele que deve dizer do que precisa. Bruna passou a 
trazer para suas narrativas reflexões baseadas no movimento "Nada sobre nós, sem nós", definido em 2004, por ocasião das celebrações do Dia Internacional das Pessoas com Deficiência. Esse movimento tem como lema trazer para a discussão o estabelecimento de políticas de inclusão mais assertivas, eficientes e eficazes pela voz de pessoas que convivem diariamente com uma deficiência, na busca de dar visibilidade a quem convive socialmente com a questão.

$\mathrm{Na}$ Convenção Internacional sobre os Direitos das Pessoas com Deficiência em 2004, esse movimento ganhou destaque, e os grupos que antes eram passivos diante das decisões políticas e sociais passaram a ser protagonistas na constituição de políticas públicas de inclusão. Isso tem ampliado as discussões sobre o tema, instituindo assim uma nova conjuntura:

Como vocês sabem (e quem não sabe, fica sabendo), minha pesquisa de mestrado é sobre a representação da pessoa com deficiência na mídia. E vocês não imaginam como é difícil encontrar gente falando a sério sobre isso. Pois bem, minha amiga Juliana Carvalho criou um evento pra ajudar a tia Bruna aqui... hehehe Vai acontecer no dia 27 de julho (quarta-feira), o Seminário Mídia e Deficiência, com a participação de Jairo Marques (o tio do Assim como você, representantes do Grupo RBS, grupo Record, grupo Bandeirantes, das faculdades de comunicação ([Faculdade de Biblioteconomia e Comunicação] FABICO, [Escola de Comunicação, Artes e Design] FAMECOS, [Universidade Luterana do Brasil] ULBRA e [Universidade do Vale do Rio dos Sinos] Unisinos) e das entidades de pessoas com deficiência pela primeira vez se unem com um objetivo: acelerar a inclusão. (SILVEIRA, 2011)

Neste post Bruna convidou seus leitores a participarem do Seminário sobre Mídia e Deficiência, para refletirem a respeito de políticas de inclusão com representantes da mídia, universidades e entidades de pessoas com deficiência. Em sua entrevista, ela declarou:
Minhas amizades aqui, muitas se deram por conta da Esclerose, muitas pelo blog e muitas por esses grupos, [...] meus amigos aqui de Porto Alegre foram se fazendo nesse... nesse círculo. E aí a minha pesquisa de mestrado foi... foi com isso, não é? Eu descobri uma linha teórica que é só sobre estudos da deficiência. Então estudos culturais, estudos sociais, assim, não vendo a doença e a deficiência como um... Só um problema biológico, não é? Mas como um problema social, que era uma coisa que eu já vinha pensando, mas eu vinha pensando sozinha então eu encontrei companheiros pra pensar junto comigo. (SILVEIRA; BURITI; VENERA, 2018)

Portanto, ela revela, continuamente, que a sua militância está focada na desconstrução social da concepção da deficiência associada a uma condição humana incapacitante, que traz como consequência situações de exclusão social. Ela faz questão de usar a palavra deficiente para provocar a reflexão e a mudança do sentido social do termo. A proposta de Bruna é levar seus leitores a refletir sobre as políticas de inclusão pela perspectiva do paciente, por meio do olhar de quem convive cotidianamente com situações de exclusão. Echavarren (2009, p. 163) afirma que "os pacientes sabem mais sobre sua doença do que os médicos. Eles se preocupam menos, ou lidam apenas com partes ou aspectos do mal". Desse modo, Bruna propõe-se a oferecer aos pacientes/seguidores um espaço para discussões sobre políticas públicas de inclusão, para que elas possam serem tecidas de forma mais condizente com a realidade dos pacientes.

Entendendo a proporção social, histórica, política e econômica que essa nova perspectiva oferece para repensarmos as políticas públicas de inclusão, as narrativas (auto)biográficas desses jovens blogueiros tornaram-se significativas na reflexão sobre a mudança de perspectiva de uma vida com esclerose múltipla. Por uma vulnerabilidade, eles se percebem em relação a um padrão social e escre- 
vem sobre suas vidas tendo em vista um novo horizonte de expectativas ou outro mundo e futuro possiveis.

Bruna reconhece que essa intenção não estava no nascimento do blog, mas não minimiza os seus efeitos:

O blog nunca foi planejado para ser uma referência, não é? Eu nunca escrevi para ser uma influenciadora digital, não é? Eu nunca pensei isso, mas foi uma coisa que aconteceu, assim, não é? Deu a calhar de, de não ter nada, não ter ninguém, não é? Sabe aquela coisa da oportunidade? [Riso] Não tinha ninguém fazendo e eu comecei a fazer num momento em que muitas pessoas estavam sendo diagnosticadas, porque também, é, estava tendo mais senso de referência no Brasil, é... Num momento em que a doença começou a ser mais divulgada por conta dessa chegada desses medicamentos, que eles precisavam ser divulgados de alguma forma, e aí a gente tem uma questão que no Brasil. (SILVEIRA; BURITI; VENERA, 2018)

Apesar de Bruna e Jota não terem a intenção de se tornarem influenciadores digitais, ao realizarem a (auto)biografia de suas vidas em rede, houve um alcance mobilizador de suas narrativas chamando a atenção de empresas farmacêuticas que fabricam e fornecem os medicamentos utilizados no tratamento da esclerose múltipla. 0 movimento também chamou a atenção das mídias locais e televisivas nacionais. Toda a repercussão trouxe visibilidade para a causa, e Bruna e Jota uniram forças com outros jovens pela rede e com a rede AME. Eles são associados e produtores de conteúdo com alcance mobilizador na construção de uma comunidade narrativa primordialmente no âmbito virtual.

O que coloca em destaque esses influenciadores digitais são os seus movimentos de subjetivação e a forma como acionam suas memórias, como compartilham suas experiências, seus saberes, em prol de uma luta coletiva, destacando-se como agentes sociais, po- líticos e ativistas de saúde. Ao dar visibilidade para assuntos ligados às políticas de inclusão, evidenciam e suscitam debates sobre políticas governamentais relacionadas a tratamentos disponíveis que apresentam maior eficiência e eficácia.

As suas posições acerca de relatos cotidianos são sempre políticas. Bruna escreveu uma vez sobre a sua saúde e a de sua irmã:

Minha irmã toma alguns remédios fornecidos pelo [Sistema Único de Saúde] SUS, e nem sempre chegam no dia certo. 0 problema, que o Estado não entende, é que a doença não dá folga só porque não tem o remédio. Uma doença progressiva como a [esclerose múltipla] EM ou o Alzheimer (a maioria dos remédios pra Alzheimer não estão na tabela do SUS), continua progredindo. Parece óbvio que algo progressivo, progride. Mas parece que nem isso alguns políticos entendem ainda. Eu fico indignada com isso. [...] É uma incoerência pagar imposto pra ter saúde e remédio e ainda assim, precisar ir à Justiça para garantir um direito adquirido [...] (SILVEIRA, 2010)

Algumas conquistas podem vir a consolidar-se mediante suas reivindicações, como é o caso de consultas públicas realizadas na rede, por meio dos blogs de saúde que se unem para ampliar as possibilidades de medicamentos disponiveis na lista do Sistema Único de Saúde (SUS), ou ao divulgarem e consultarem a opinião pública sobre determinada medicação, na realização de campanhas que aumentem as possibilidades de tratamento do paciente com esclerose múltipla:

Como participar da Consulta Pública e votar pela Incorporação do Medicamento: De 08 a 28 de abril, o cidadão poderá dar sua opinião a respeito da incorporação do Fingolimode pelo SUS. [...] 0 mecanismo é importante para que os órgãos responsáveis possam tomar decisões mais democráticas e transparentes. [...] $\mathrm{O}$ cadastro é rápido e pode ser feito no link http:/ / migre.me/iG4sA. A consulta pública do Fingolimode pode ser acessada em http://migre.me/ 
iG4qA. Entrem no site, assinem e compartilhem essa consulta pública. É importante! (SILVEIRA, 2014a)

Bruna entende o contexto político em que seu cotidiano está inserido e mobiliza a indústria farmacêutica a favor de suas bandeiras. Durante a entrevista, no decorrer da pesquisa, a jovem explicou como esse movimento ativista funciona e como indústrias farmacêuticas patrocinam eventos e campanhas, para pacientes e associações:

No Brasil, a indústria farmacêutica não pode fazer propaganda, ela não pode. A indústria farmacêutica não pode falar diretamente com o paciente, isso é uma questão de complaising. Quem pode falar com o paciente é a associação, é o blogueiro, é, são outras, é, são eventos. Então, para eles é importante a gente estar junto com eles, porque é a única forma do paciente, saber, que eles existem. Então assim, juntou todo um, um contexto, assim, econômico, social, histórico, para que [...] isso acontecesse, assim (SILVEIRA; BURITI; VENERA, 2018)

Esse processo de reposicionamento da forma como os ativismos sociais e políticos têm acionado seus direitos utiliza a cultura das redes sociais para provocar mudanças na rota de como têm sido gerenciadas as políticas públicas. Ao acompanhar esses movimentos de subjetivação na conjuntura social e política, em que ciberativistas se movimentam, integrando os movimentos sociais, estabelecendo pontos de apoio no ciberespaço, percebemos que o modo como eles atuam é autônomo, diante das possibilidades dos sistemas de comunicação. Eles promovem suas lutas sociais e políticas para a dinâmica do ciberespaço, reivindicam nesse ambiente de discussão mudanças de perspectivas e exploram os sistemas comunicacionais, no entanto essa autonomia não é de todo individualizada, mas sim coletiva, porque é conectada em uma multiplicidade de pontos em rede. Dessa maneira, é dada visi- bilidade para a comunidade, e uma luta que seria individual passa a ser coletiva. Ou seja, "as redes sociais não são pré-construídas pelas ferramentas e sim apropriadas pelos atores sociais que thes conferem sentido e que as adaptam para suas práticas sociais" (RECUERO, 2014, p. 20).

Diante desses novos territórios visitados, ao socializarem suas histórias, experiências, expectativas, medos, os saberes são compartilhados, novos arranjos sociais estruturamse em rede, na qual as discussões transitam e ganham força e visibilidade. Percebemos que as narrativas (auto)biográficas de Bruna e Jota, apesar de ser leituras microssociais, passam a agregar valores sociais e políticos culminantes para a construção de políticas públicas de inclusão mais condizentes com as necessidades das pessoas. Destarte, ao debruçarmos sobre suas narrativas (auto)biográficas, constituídas nos fluxos interativos do ciberespaço, diante do diagnóstico da esclerose múltipla, verificamos que os dois se configuram como agentes sociais e políticos. Entendemos que suas histórias de vida, assim como suas práticas narrativas, fazem parte desse movimento de luta em prol de políticas públicas de inclusão mais assertivas e democráticas.

Logo, compreendemos que suas histórias de vida e seus movimentos de aprendizado com a doença são significativos para a constituição de novas perspectivas sobre o processo de adoecimento. Assim, suas histórias de vida tornaram-se representativas para um grupo de jovens diagnosticados com esclerose múltipla, e isso levou Jota e Bruna a serem reconhecidos como influenciadores sociais. A materialização de suas memórias em seus blogs oportuniza jovens recém-diagnosticados com esclerose múltipla a ter acesso a uma perspectiva da doença pelo olhar do paciente, acionando suas memórias afetivas, de vulnerabilidade e de potência. 
Apesar de a intenção de seus blogs não pertencer ao campo do patrimônio, não se trata aqui de defender a patrimonialização de suas memórias ou de suas histórias de vida. Suas narrativas levaram à reflexão acerca da função social do movimento em rede dessas comunidades narrativas e do valor da narrativa como ferramenta política para um novo pacto civilizatório. As reflexões na biografia dessas duas vidas apresentam processos de ressignificações de memórias e identidades, de mudanças de perspectivas de futuros e mundos possiveis e de construção de novas subjetivações, provocadas pelas mudanças de suas condições de vida. Eles utilizam a blogosfera como um lugar político de resistência, a fim de refletir sobre suas lutas diárias contra discursos de intolerância construídos social e culturalmente. A condição de doença crônica apresenta a eles a chance de refletir a respeito de como significamos o mundo sob alguns padrões, e eles não se furtam disso: "Ter uma doença e ser bem -apessoada, inteligente, educada é quase um crime. Ter uma doença e ser nova então, é um absurdo. As pessoas perguntam 'mas como? tão novinha?' eu sempre respondo 'desculpa, eu não escolhi não, fora isso, doença não tem idade"' (SILVEIRA, 2013).

Veiga-Neto (2001) destaca que ao longo da modernidade ocorreram deslocamentos no sentido do significado da palavra anormal, que saiu do plano cuja ênfase estava sobre a morfologia e a conduta (dos corpos) e passou para a economia e a privação (sem-teto, sem-emprego, sem-cidadania). O autor afirma que a inversão da lógica neoliberal - em que critérios são fundamentalmente econômicos, como a capacidade de consumir e a competência/expertise para fazer as melhores escolhas - é atribuir como critérios para classificar as pessoas a régua do normal ou anormal. Assim, sob essa nova denominação genérica - os anormais -, abrigam-se diferentes identidades flutuantes cujos significados se estabelecem discursivamente em processos que, no campo dos estudos culturais, se costuma chamar de políticas de identidade.

Trata-se de processos que estão sempre atravessados por relações de poder, de cuja dinâmica decorre o caráter instável e flutuante dessas e de quaisquer outras identidades culturais (VEIGA-NETO, 2001, p. 106). De acordo com o autor, a modernidade caracteriza-se pela intolerância à diferença, marcada pela vontade de ordem. Veiga-Neto (2001) deixa claro que toda operação de ordenamento é sempre naturalizada. Diante desse fato, ele acredita que "tematizar essas dificuldades pode contribuir para desnaturalizá-las, desconstruí-las para mais uma vez mostrar o quanto elas são contingentes, justamente porque advêm de relações que são construídas social e discursivamente" (VEIGA-NETO, 2001, p. 110), dando ênfase à importância de desconstruir uma visão essencialista para a definição de identidade das pessoas, a fim de promover uma visão plural das identidades e identificações de todos. Sendo assim,

as identidades não são nunca unificadas; que elas são, na modernidade tardia, cada vez mais fragmentadas e fraturadas, que elas não são, nunca, singulares, mas multiplamente construídas ao longo de discursos, práticas e posições que podem se cruzar ou ser antagônicos. As identidades estão sujeitas a uma historicização radical, estando constantemente em processo de mudança e transformação. (HALL, 2000, p. 108)

Bruna e Jota trazem essa reflexão em seus posts, e o rapaz escreve sobre o constante fazer e refazer de suas identidades diante das mudanças: "Desde o diagnóstico foi um constante fazer e refazer de identidades e desejos, que aprendi a viver e amar a mudança; viver no presente e não ficar preso naquilo que fui e naquilo que gostaria de ser" (SAN- 
TOS JUNIOR; BURITI; VENERA, 2018). Em seu post "Quem sou eu?", Bruna apresenta suas múltiplas identidades:

Eu sou esclerosada [...]. Eu sou mãe do Francisco. E isso tem a ver com muito trabalho, porque ser mãe é trabalho de $24 \mathrm{~h}$, sem descanso. [...] Eu sou esposa, companheira do Jota, outro esclerosado. [...] Eu sou ativista do movimento das pessoas com deficiência. Eu sou feminista. Eu sou filha. Eu sou neta. Eu sou eterna estudante. Eu sou sonhadora. Eu sou uma chata de galocha perfeccionista. Eu sou uma leitora voraz. Mas eu escrevo mais até do que leio. (SILVEIRA, 2017)

Entende-se que suas identidades se constituem nessas relações sociais e culturais. Tanto Bruna quanto Jota apresentam esse processo constante de fazer e de se refazer em suas narrativas (auto)biográficas, que passam a ganhar direcionamentos e desdobramentos sociais na constituição de suas múltiplas identidades. Assim, suas histórias de vida vão sendo estruturadas e reestruturadas com base em narrativas e por meio delas, as quais são utilizadas como apoio para o processo de aprendizagem sobre a vida, como uma reorganização da percepção de si.

\section{Algumas reflexões}

No campo do patrimônio, compreendemos que as narrativas constituem parte do valor de um bem, mas também e especialmente integram a formação pessoal de um sujeito, como Bruner (2014, p. 75) afirma: “A criação do eu é uma arte narrativa". São ferramentas mobilizadas no fazer de uma vida, de um mundo e, quiçá, de outro mundo possivel, mais democrático e participativo. Diante das vulnerabilidades, como no caso dos diagnósticos de uma doença crônica, por exemplo, foi por meio de narrativas dos blogueiros que desdobramentos e proliferações de suas identidades e subjetividades surgiram no ciberespaço em prol de ações políticas, sociais e culturais efetivas. A observação desses even- tos no campo do patrimônio nos faz repensar os valores patrimoniais das narrativas agora, no cotidiano e no fazer da vida.

Observamos esse movimento que se organiza de forma distributiva por dois ciberativistas da saúde. As suas experiências, seus processos de formação e de aprendizagem e suas convicções sociais, religiosas e políticas são socializados em seus blogs, e suas palavras são articuladas e passam a receber novos sentidos sobre o processo de adoecimento em que estão envolvidos, mas apontam ainda para reflexões que convidam para pensar acerca de valores e das memórias coletivas já cristalizadas, como por exemplo o normal e o patológico, o deficiente e o eficiente. A construção dessa realidade, por meio de um cenário virtual, apresenta estratégias identitárias marcadas de "metamemórias", ou seja, da representação que cada indivíduo faz de sua própria memória, da perspectiva ou consciência que se tem da doença no coletivo. Essa visão está intrinsecamente relacionada a fatores sociais e culturais presentes antes do evento e influem na formação da consciência, sendo assim reconhecida por Candau (2016) como "uma memória reivindicada" e "ostensiva", capaz de conectar vidas que se identificam, despertar empatia, construir identidades e mobilizar grupos.

Essas narrativas dispararam reflexões no campo do patrimônio como um elogio às práticas narrativas, pensadas como direito humano de expressão. Como ferramentas, as narrativas possuem usos políticos para a construção de novos pactos civilizatórios em um mundo onde as vulnerabilidades - como doenças, imigração forçada, entre outros - funcionam como condição de vida, e não como diferenças que coloquem o sujeito em condição deficitária. As narrativas de memória funcionam também como potência de vida quando elas não apenas expressam, porém fundam a humanidade. Mais do que apenas a função da linguagem, 
mas também a narrativa da memória no jogo do tempo, daquilo que lembramos e mobilizamos em função de um desejo de futuro e de existência outra. Pensadas dessa forma, as narrativas revelam-se patrimônios da humanidade, tesouros da vida e do exercício dos direitos humanos.

\section{Referências}

BRUNER, Jerome. Fabricando Histórias: Direito, Literatura, Vida. São Paulo: Letra e Voz, 2014.

CANDAU, Joël. Memória e identidade. São Paulo: Contexto, 2011.

CHAUÍ, Marilena. Cidadania cultural: o direito à cultura. São Paulo: Fundação Perseu Abramo, 1989.

ECHAVARREN, Roberto. Tu bata blanca, el pastillero mío, ambos trofeos. In: GUERRERO, Javier; BOUZAGLO, Natalie (orgs.). Excesos del cuerpo: ficciones de contagio y enfermedad en América Latina. Buenos Aires: Eterna Cadencia, 2009. p. 162-205.

FOUCAULT, Michael. Hermenêutica do sujeito. 3. ed. São Paulo: Martins Fontes, 2010.

GADAMER, Hans-Georg. Verdade e método. Petrópolis: Vozes, 1997.

HALBWACHS, Maurice. A memória coletiva. Tradução de Beatriz Sidou. São Paulo: Centauro, 2006.

HALL, Stuart. Quem precisa da identidade? In: SILVA, Tomaz Tadeu (org.). Identidade e diferença: a perspectiva dos estudos culturais. Petrópolis: Vozes, 2000. p. 103-133.

KOSELLECK, Reinhart. Futuro passado: contribuição à semântica dos tempos históricos. Rio de Janeiro: Contraponto / PUC-RIO, 2014.

LE GOFF, Jacques. Memória. In: (org.). História e memória. 5. ed. Campinas: Unicamp, 2003. p. 419-476.

LEI 12.196, de 02 de maio de 2002. Disponivel em: < https:/ / bit.ly/3fmGrNi . Acesso em: 31 maio 2019.

MORGADO, Isabel. A pressão política sobre os líderes de opinião. A luta pela soberania do tempo. Comunicação e Política, Covilhã, 2005.
MUCHAIL, Sauma Tannus. Foucault, mestre do cuidado: textos sobre hermenêutica do sujeito. São Paulo: Loyola, 2011.

MULTIPLE SCLEROSIS INTERNATIONAL FEDERATION.

Atlas da Esclerose Múltipla. Mapeamento da esclerose múltipla no mundo. Tradução da Associação Brasileira de Esclerose Múltipla. Londres: Multiple Sclerosis International Federation, 2013.

RECUERO, Raquel. A conversação em rede: comunicação mediada pelo computador. Porto Alegre: Sulina, 2014.

SANTOS JUNIOR, Jaime Fernando dos. Começando a blogar na AME. Blog do Jota, Porto Alegre, 17 abr. 2015. Disponivel em: <http://amigosmultiplos.org. $\mathrm{br} /$ jota/single-post/2015/04/17/>. Acesso em: 22 maio 2019.

EM e Eu (Parte III) - Tempo e privilégio ou o que eu desejo perder. Blog do Jota, Porto Alegre, 27 fev. 2019. Disponivel em: <http://amigosmultiplos. org.br/jota/single-post/2019/02/27/>. Acesso em: 22 maio 2019.

EM e Família (Parte IV) - Obrigado! Blog do Jota, Porto Alegre, 3 jan. 2018. Disponivel em: <http://amigosmultiplos.org.br/jota/single -post/2018/01/03/>. Acesso em: 22 maio 2019.

SANTOS JUNIOR, Jaime Fernando dos; BURITI, Roberta Fernandes; VENERA, Raquel A. L. S. Entrevista de história oral de vida. Acervo da pesquisa Memórias Múltiplas e Patrimônio Cultural em Rede: o Desafio (Auto)Biográfico diante da Ameaça da Perda. São Paulo: Museu da Pessoa; Joinville: Laboratório de História Oral da Univille, 2018.

SILVEIRA, Bruna Rocha. Bem-vindos à minha vida. Esclerose Múltipla e Eu, Porto Alegre, 11 mar. 2009. Disponivel em: <http://esclerosemultiplaeeu.blogspot.com/single-post/2009/03/11/Bem-vindos-àminha-vida>. Acesso em: 31 out. 2019. Carta ao marido da jovem grávida. Esclerose Múltipla e Eu, Porto Alegre, 30 nov. 2016a. Dis- 
ponivel em: <http://esclerosemultiplaeeu.blogspot. com/single-post/2016/11/30/Carta-ao-Marido-daJovem-Grávida>. Acesso em: 31 out. 2019.

. Classificados esclerosados. Esclerose Múltipla e Eu, Porto Alegre, 3 maio 2015a. Disponivel em: <http:/ /esclerosemultiplaeeu.blogspot.com/single-post/2015/05/03/Classificados-Esclerosados>. Acesso em: 31 out. 2019.

Consulta Pública Fingolimode. Esclerose Múltipla e Eu, Porto Alegre, 8 abr. 2014a. Disponivel em: <http://esclerosemultiplaeeu.blogspot.com/ single-post/2014/04/08/>. Acesso em: 31 out. 2019.

Incluir é pra quem? Esclerose Múltipla e Eu, Porto Alegre, 14 maio 2015b. Disponivel em: $<$ http:/ /esclerosemultiplaeeu.blogspot.com/single-post/2015/05/14/Incluir-é-pra-quem?>. Acesso em: 31 out. 2019.

Manifesto dos Crônicos. Crônicos do dia a

dia. Disponivel em: <https://bit.ly/2Z9YOyc >. Acesso em: 20 dez. 2019.

Mural de avisos. Esclerose Múltipla e Eu, Porto Alegre, 17 jul. 2011. Disponível em: <http:// esclerosemultiplaeeu.blogspot.com/single -post/2011/07/17/>. Acesso em: 31 out. 2019.

Nada sobre nós sem nós. Esclerose Múltipla e Eu, Porto Alegre, 7 jan. 2016b. Disponivel em: <http:/ /esclerosemultiplaeeu.blogspot.com/single -post/2016/01/07/ Nada-sobre-nós-sem-nós>. Acesso em: 31 out. 2019.

. O Encontro do Dia Mundial da EM foi show. Esclerose Múltipla e Eu, Porto Alegre, 27 maio 2013. Disponivel em: <http:/ /esclerosemultiplaeeu.blogspot.com/single-post/2013/05/27/>. Acesso em: 31 out. 2019.

. Porquê escrevo. Esclerose Múltipla e Eu, Porto Alegre, 11 mar. 2014b. Disponivel em: <http://esclerosemultiplaeeu.blogspot.com/single-post/2014/03/11/ Porquê-escrevo>. Acesso em: 31 out. 2019.

Quem sou eu? Esclerose Múltipla e Eu, Porto Alegre, 24 jul. 2017. Disponivel em: <http:// esclerosemultiplaeeu.blogspot.com/single -post/2017/07/24/>. Acesso em: 31 out. 2019.
Remédio na justiça. Esclerose Múltipla

e Eu, Porto Alegre, 18 mar. 2010. Disponivel em: <http://esclerosemultiplaeeu.blogspot.com/single -post/2010/03/18/>. Acesso em: 31 out. 2019.

Dor compartilhada é dor diminuída: autobiografia e formação identitária em blogs de pessoas em condição de doença. 187f. Tese de Doutorado. (Faculdade de Educação) Porto Alegre, 2016.

SILVEIRA, Bruna Rocha; BURITI, Roberta Fernandes; VENERA, Raquel A. L. S. Entrevista de história oral de vida. Acervo da pesquisa Memórias Múltiplas e Patrimônio Cultural em Rede: o Desafio (Auto) Biográfico diante da Ameaça da Perda. São Paulo: Museu da Pessoa; Joinville: Laboratório de História Oral da Univille, 2018.

SZYMCZAK, Maureen B.; VENERA, Raquel. A ativação valorativa das histórias de vidas no Museu da Pessoa. Anais do Museu Histórico Nacional, v. 51, p. 174190, 2019.

TAYLOR, Diana. Performance e patrimônio cultural intangivel. PóS, v. 1, n. 1, p. 91-103, 2011. Disponivel em: <https://periodicos.ufmg.br/index.php/revistapos/article/view/15407/12264>. Acesso em: 27 dez. 2019.

THOMPSON, Paul. Histórias de vida como patrimônio da humanidade. In: WORCMAN, K.; PEREIRA, J. V. (orgs.). História falada: memória, rede e mudança social. São Paulo: Sesc; Museu da Pessoa; Imprensa Oficial de SP, 2006.

VALENÇA, Nilton. Patrimônios vivos de Pernambuco: uma análise sobre a cessão dos direitos patrimoniais de autor. 59f. Monografia (Formação de Gestores Culturais dos Estados do Nordeste) - Instituto de Humanidades, Artes e Ciências Professor Milton Santos, Universidade Federal da Bahia, Salvador, 2014.

VEIGA-NETO, Alfredo. Incluir para excluir. In: LARROSA, Jorge; SKLIAR, Carlos (orgs.). Habitantes de Babel: políticas e poéticas da diferença. Belo Horizonte: Autêntica, 2001. p. 105-118.

Recebido em: 21.02.2020 Revisado em: 28.05.2020 Aprovado em: 31.05 .2020 
Raquel Alvarenga Sena Venera é doutora em Educação pela Universidade Estadual de Campinas (Unicamp). Professora do Programa de Pós-Graduação em Patrimônio Cultural e Sociedade e do curso de História da Universidade da Região de Joinville. Líder do Grupo de Pesquisa Subjetividades e (Auto)Biografias. E-mail: raquelsenavenera@gmail.com

Roberta Fernandes Buriti é mestra em Patrimônio Cultural e Sociedade pela Universidade da Região de Joinville. Integra os grupos de pesquisas Subjetividades e (Auto)biografias e Imbricamentos de Linguagens. Professora da rede municipal de educação de São Francisco do Sul. E-mail: robertaburity@hotmail.com 